\title{
Clinical applications of the sustained-release dexamethasone implant for treatment of macular edema
}

This article was published in the following Dove Press journal:

Clinical Ophthalmology

28 January $201 \mathrm{I}$

Number of times this article has been viewed

Rocío Herrero-Vanrell' Jose Augusto Cardillo² Baruch D Kuppermann ${ }^{3}$

'Department of Pharmacy and Pharmaceutical Technology, School of Pharmacy, Complutense University, Madrid, Spain; ${ }^{2}$ Hospital de Olhos de Araraquara, Araraquara, São Paulo, Brazil; ${ }^{3}$ Gavin Herbert Eye Institute, University of California, Irvine, CA, USA
Correspondence: Baruch D Kuppermann Gavin Herbert Eye Institute, Department of Ophthalmology, University of California, I 8 Med Surge I,

Irvine, CA 92697-4375, USA

Tel + I 9498246256

Fax +I 9498244015

Email bdkupper@uci.edu

\begin{abstract}
Macular edema is one of the leading causes of vision loss among patients with retinal vein occlusion, diabetic retinopathy, and posterior chamber inflammatory disease. However, the treatment of macular edema is considerably limited by the difficulty in delivering effective doses of therapeutic agents into the vitreous cavity. In recent years, the development of a sustained-release dexamethasone intravitreal implant $\left(\right.$ Ozurdex $\left.^{\circledR}\right)$ has enabled more controlled drug release at a stable rate over a long period of time, with a potentially lower rate of adverse events. Clinical studies indicate that this dexamethasone implant is a promising new treatment option for patients with persistent macular edema resulting from retinal vein occlusion, diabetic retinopathy, and uveitis or Irvine-Gass syndrome.
\end{abstract}

Keywords: diabetic retinopathy, macular edema, Ozurdex ${ }^{\circledR}$, posterior-segment inflammatory disease, retinal vein occlusion, sustained-release dexamethasone implant

\section{Introduction}

Macular edema is thought to be due to abnormal retinal capillary permeability, manifesting by extravascular swelling in the macula. ${ }^{1}$ Macular edema is associated with a variety of underlying diseases, but is most commonly seen in patients with retinal venous occlusion, diabetic retinopathy, and posterior-segment inflammatory disease..$^{1-3}$ Current evidence suggests that the pathological processes leading to macular edema involve numerous inflammatory cells, cytokines, growth factors, and intercellular adhesion molecules, which are associated with increased vascular permeability, breakdown of the blood-retinal barrier, remodeling of the extracellular matrix, and upregulation of proangiogenic factors. ${ }^{4-8}$

Macular edema is one of the leading causes of vision loss among patients with retinal vein occlusion, diabetic retinopathy, and posterior-segment inflammatory disease. However, the treatment of macular edema is considerably limited by the difficulty in delivering effective doses of therapeutic agents into the vitreous cavity. While various therapeutic agents, such as antivascular endothelial growth factor, along with an array of technologies to circumvent the blood-retinal barrier are under development, ${ }^{9-12}$ a sustained-release dexamethasone implant has recently become available for the treatment of macular edema secondary to a variety of underlying diseases.

\section{Treatment of macular edema}

Traditionally, the main treatment options for macular edema are laser photocoagulation and anti-inflammatory therapy depending on etiology. Laser photocoagulation prevents 
further vision loss in patients with macular edema caused by diabetes and retinal vein occlusion. ${ }^{13-15}$ However, the prevention of visual decline is not always uniform, and some patients can be refractory to laser treatment. In addition, this mode of therapy is associated with moderate visual loss, a diminished visual field, and reduced color vision and contrast sensitivity. ${ }^{16-18}$

Corticosteroids are potent anti-inflammatory agents that can counteract many of the pathological processes thought to play a role in the development of macular edema. Corticosteroids prevent leukocyte migration, reduce fibrin deposition, stabilize endothelial cell tight junctions, and inhibit synthesis of vascular endothelial growth factor, prostaglandins, and proinflammatory cytokines. ${ }^{19}$ However, the route of corticosteroid administration dramatically affects the risk to benefit ratio of corticosteroid therapy (Table 1). Oral corticosteroids are complicated with many adverse events, including osteoporosis, a Cushingoid state, adrenal suppression, and exacerbation of diabetes. ${ }^{20-23}$ Topical, peribulbar, and subconjunctival corticosteroid administrations deliver suboptimal vitreous drug levels (Table 1) with a very short half-life (approximately 3.5 hours) and are associated with relatively high systemic corticosteroid concentrations, which can potentially be accompanied by significant adverse events. ${ }^{24-28}$ On the other hand, direct intravitreal corticosteroid administration bypasses the blood-retinal barrier, leading to high local drug concentrations with no or little systemic adverse events.

Given the short half-life of dexamethasone in the vitreous cavity, the crystalline form of a lipophilic corticosteroid, triamcinolone acetonide (Kenalog ${ }^{\circledR}-40$, Bristol-Myers Squibb, Princeton, NJ), with a vitreous residence time of several months, gained widespread use for treatment of macular edema secondary to retinal vein occlusion, diabetic retinopathy, and uveitis, in spite of the lack of controlled, randomized studies demonstrating that its efficacy exceeds the risks. ${ }^{29-33}$ Recent randomized trials demonstrated that intravitreal triamcinolone acetonide was more effective

Table I Traditional routes of dexamethasone administration provide suboptimal vitreous levels and high systemic concentrations

\begin{tabular}{llll}
\hline Route & Dose $(\mathbf{m g})$ & $\begin{array}{l}\text { Vitreous } \mathbf{C}_{\text {max }} \\
(\mathbf{n g} / \mathbf{m L})\end{array}$ & $\begin{array}{l}\text { Serum } \mathbf{C}_{\text {max }} \\
(\mathbf{n g} / \mathbf{m L})\end{array}$ \\
\hline Oral & 7.5 & 5.2 & 61.6 \\
Topical & $0.5^{\mathrm{a}}$ & 1.1 & 0.7 \\
Peribulbar & 3.8 & 13 & 60 \\
Subconjunctival & 1.9 & 72.5 & 32.4 \\
\hline
\end{tabular}

Note: a $10-11$ drops from $0.1 \%$ dexamethasone solution every hour. Abbreviation: $\mathrm{C}_{\max }$, maximum concentration. than observation in patients with macular edema secondary to central retinal vein occlusion, and as effective as laser therapy in patients with macular edema secondary to branch retinal vein occlusion in improving visual acuity. ${ }^{34,35}$ In diabetic patients with macular edema, laser therapy was more effective than intravitreal triamcinolone acetonide in improving visual acuity at the study primary endpoint of two years, although triamcinolone acetonide was initially more effective than laser at four months. ${ }^{36}$ However, in those studies, intravitreal triamcinolone acetonide was associated with a high rate of elevated intraocular pressure and cataract formation, two ocular adverse events that have been linked most commonly to corticosteroid therapy. ${ }^{37-39}$ The incidence of $\mathrm{a} \geq 10 \mathrm{mmHg}$ increase in intraocular pressure from baseline ranged from $24 \%$ to $50 \%$ in the intravitreal triamcinolone acetonide $4 \mathrm{mg}$ group compared with $2 \%$ to $13 \%$ in the observation or laser therapy group. ${ }^{34-36}$ The incidence of cataract surgery ranged from $23 \%$ to $51 \%$ in the intravitreal triamcinolone acetonide $4 \mathrm{mg}$ group compared with $0 \%$ to $13 \%$ in the observation or laser therapy group.

In recent years, the development of a sustained-release intravitreal dexamethasone implant $\left(\right.$ Ozurdex $^{\circledR}$, Allergan Inc, Irvine, CA) enabled more controlled delivery of drug, with a potentially lower rate of adverse events. The dexamethasone implant is now emerging as a potential treatment for macular edema arising from retinal vein occlusion, diabetic retinopathy, and uveitis.

\section{Sustained-release dexamethasone implant}

Among the corticosteroids, dexamethasone is one of the most potent, with an anti-inflammatory activity that is six-fold greater than that of triamcinolone and 30-fold greater than cortisol. ${ }^{40}$ In the dexamethasone implant, the active drug is dispersed through a biodegradable copolymer of lactic acid and glycolic acid (PLGA), forming a matrix structure (Novadur ${ }^{\mathrm{TM}}$, Allergan Inc). ${ }^{41}$ These polymers have been used in a number of products, including absorbable sutures. ${ }^{42,43}$ For several years, PLGA has been used to prepare nanoparticles and microparticles for intraocular drug delivery. These drug delivery systems have been tested in animal models and humans. ${ }^{44-47}$

In the early clinical studies, the dexamethasone implant was surgically implanted into the vitreous cavity via a pars plana incision. ${ }^{48-50}$ Subsequently, a single-use, sutureless dexamethasone posterior-segment drug delivery system (DDS) applicator was developed, allowing injection of the 
dexamethasone implant in the office rather than in a surgical setting (Figure 1). ${ }^{51}$ The dexamethasone implant was observed for six months after implantation in monkey eyes. ${ }^{52}$ The dexamethasone implant releases the drug by diffusion in a biphasic fashion, with higher doses for up to six weeks followed by lower doses for up to six months (Figure 2). ${ }^{52}$ Experience has shown that PLGA is biocompatible and, inside the eye, is metabolized into carbon dioxide and water. Thus, sequential implants can be placed in an office setting without the need for surgical removal. The dexamethasone implant is indicated for the treatment of macular edema following retinal vein occlusion. ${ }^{41}$ The safety and efficacy of the dexamethasone implant have also been investigated in uveitic, diabetic, and vitrectomized diabetic patients with macular edema.

\section{Phase II studies}

A Phase II trial evaluated the safety and efficacy of the dexamethasone implant in patients with persistent macular edema. ${ }^{49}$ This study enrolled patients $\geq 12$ years of age with a best-corrected visual acuity (BCVA) of 20/40 to 20/200 because of clinically detectable macular edema persisting for $\geq 90$ days after laser or medical therapy. Macular edema was secondary to central retinal vein occlusion, branch retinal vein occlusion, diabetic retinopathy, uveitis, or Irvine-Gass

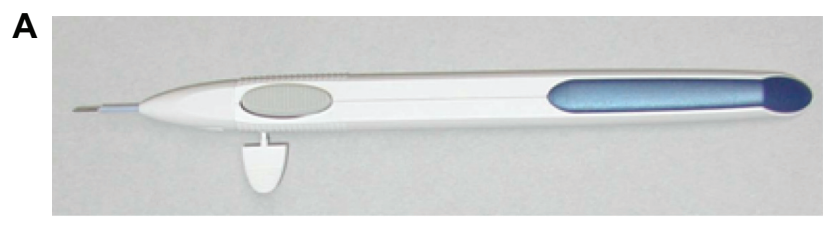

B

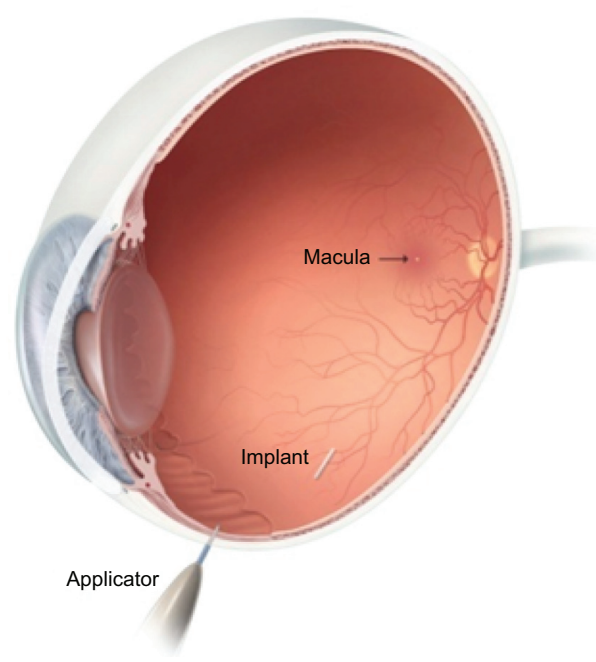

Figure I Dexamethasone Posterior Segment Drug Delivery System ${ }^{\circledR}$ Applicator and approximate vitreous location of dexamethasone implant after insertion. The implant is approximately $6 \mathrm{~mm}$ long and is inserted into the vitreous cavity through the 22-gauge needle of the applicator.

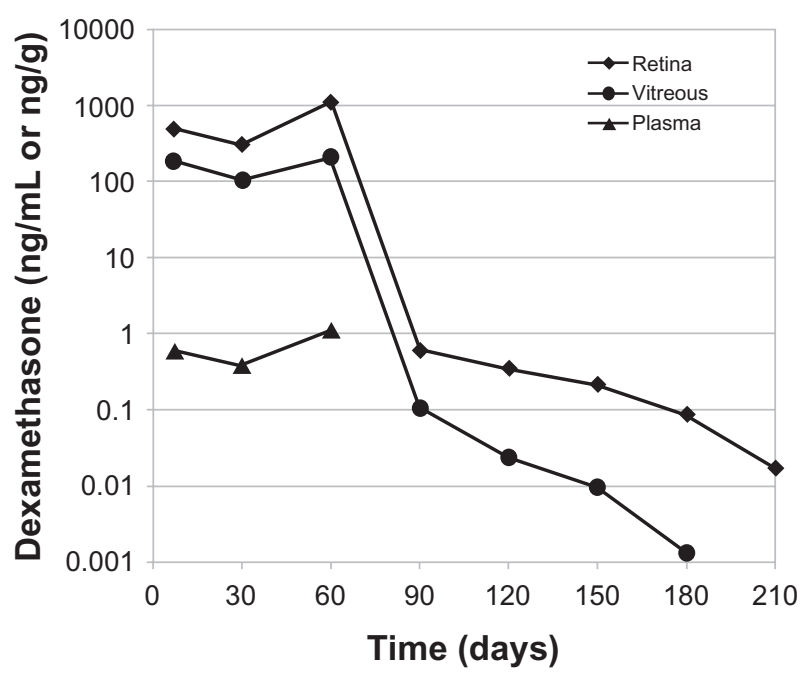

Figure 2 Temporal kinetics of dexamethasone concentrations in the vitreous cavity, retina, and plasma following placement of the $0.7 \mathrm{mg}$ dexamethasone implant in monkeys. The dexamethasone concentration was below the minimum detection limit in plasma after day 60.

syndrome. A total of 315 patients were randomized in a 1:1:1 ratio to observation or to treatment with a surgically placed dexamethasone implant at two doses, ie, $0.35 \mathrm{mg}$ or $0.7 \mathrm{mg}$. The primary outcome measure was the proportion of patients who achieved at least a 10-letter improvement in BCVA at day $90 .{ }^{49}$

The proportion of patients with $\mathrm{a} \geq 10$-letter or $\geq 15$-letter improvement in BCVA at day 90 was significantly higher in the $0.7 \mathrm{mg}$ dexamethasone implant group compared with the observation group. At day 180, a significantly greater proportion of patients treated with the $0.7 \mathrm{mg}$ dexamethasone implant achieved a $\geq 10$-letter or $\geq 15$-letter improvement in BCVA (Figure 3). There were no statistically significant differences in improvement of BCVA between the $0.35 \mathrm{mg}$ dexamethasone implant group and the observation group at day 90 or $180 .{ }^{49}$ Treatment with dexamethasone implant at either dose $(0.35 \mathrm{mg}$ or $0.7 \mathrm{mg})$ significantly decreased central retinal thickness and fluorescein angiographic leakage at day 90 compared with the observation group. ${ }^{49}$

In the Phase II study, the dexamethasone implant was well tolerated and had a favorable safety profile. The incidence of $\mathrm{a} \geq 10 \mathrm{mmHg}$ increase in intraocular pressure from baseline was $3 \%$ in the observation group, $12 \%$ in the $0.35 \mathrm{mg}$ dexamethasone implant group, and $17 \%$ in the $0.7 \mathrm{mg}$ dexamethasone implant group. Most of these patients $(>65 \%)$ had only a single occurrence of an intraocular pressure increase of this magnitude or greater. No significant between-group differences were found in the number of reports of cataract. However, treatment-related cataract formation may take longer than 180 days to become apparent. ${ }^{49}$ 


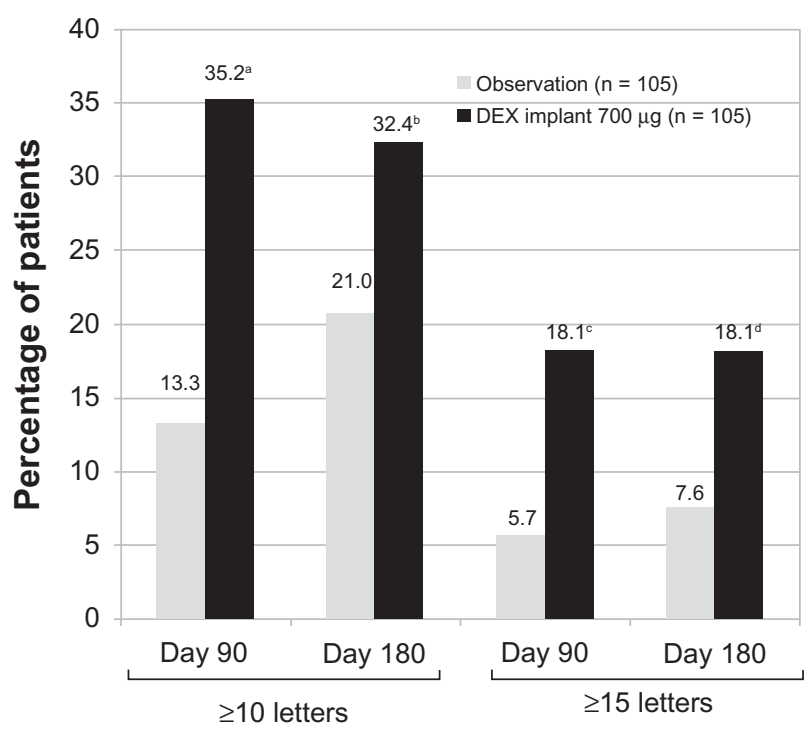

Improvement in visual acuity

Figure 3 Percentage of patients with a $\geq 10$-letter or a $\geq 15$-letter improvement in best corrected visual acuity following treatment with the $0.7 \mathrm{mg}$ dexamethasone implant at days 90 and 180 .

Notes: ${ }^{a} P<0.001$, ${ }^{b} P=0.06,{ }^{c} P=0.006$, and ${ }^{d} P=0.02$ compared with observation. A $P<0.025$ was considered a statistically significant difference.

Abbreviation: DEX, dexamethasone.

In the Phase II study, subset analyses were performed to evaluate whether the treatment effect was similar across the underlying causes of persistent macular edema. These analyses showed that the improvement in BCVA at day 90 was more favorable in the $0.7 \mathrm{mg}$ dexamethasone implant group than in the observation group, regardless of the underlying cause of macular edema (Figure 4) ${ }^{48-50}$ In a subset of patients with retinal vein occlusion, an improvement in

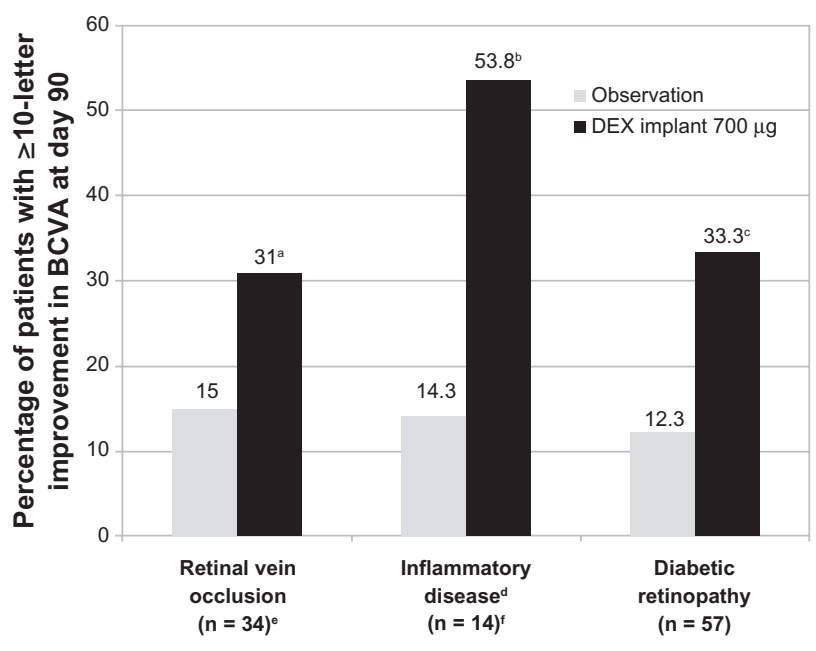

Figure 4 Efficacy of the dexamethasone implant in improving BCVA stratified by the underlying cause of macular edema in patients who participated in the Phase II trial. Notes: ${ }^{a} P$ not determined; ${ }^{b} P=0.029$ and ${ }^{c} P=0.007$ compared with the observation

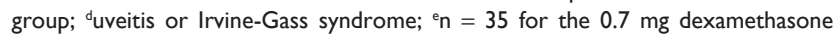
implant; ${ }^{\prime} n=13$ for the $0.7 \mathrm{mg}$ dexamethasone implant.

Abbreviations: DEX, dexamethasone; BVCA, best corrected visual acuity.
BCVA of $\geq 10$ letters at day 90 was observed in $31 \%$ of patients treated with the $0.7 \mathrm{mg}$ dexamethasone implant compared with $15 \%$ of patients in the observation group. ${ }^{49}$ In a subset of patients with uveitis or Irvine-Gass syndrome, an improvement in BCVA of $\geq 10$ letters at day 90 was observed in $53.8 \%$ of patients treated with the $0.7 \mathrm{mg}$ dexamethasone implant compared with $14.3 \%$ of patients in the observation group..$^{50} \mathrm{In}$ a subset of patients with diabetic macular edema, an improvement in BCVA of $\geq 10$ letters at day 90 was observed in $33.3 \%$ of patients treated with the $0.7 \mathrm{mg}$ dexamethasone implant compared with $12.3 \%$ of patients in the observation group. ${ }^{48}$ Among diabetic patients, this significant difference was maintained when patients were stratified according to their pattern of diabetic macular edema, ie, focal, diffuse, cystoid, and both cystoid and diffuse. ${ }^{53}$ Overall, the pattern of adverse events seen in these subpopulations was similar to that seen in the overall population of patients included in the Phase II study. ${ }^{48-50}$

\section{Phase III studies}

Two identical, multicenter, masked, randomized, clinical trials evaluated the safety and efficacy of the dexamethasone implant as compared with sham in eyes with vision loss due to clinically detectable macular edema associated with either central or branch retinal vein occlusion. ${ }^{54} \mathrm{~A}$ total of 1267 patients was randomized in a 1:1:1 ratio to either a sham procedure or treatment with the dexamethasone implant at the dose of $0.35 \mathrm{mg}$ or $0.7 \mathrm{mg}$. The dexamethasone implant was inserted into the vitreous cavity through the pars plana by a single-use DDS applicator. The primary efficacy outcome for the pooled data from the two Phase III studies was the time to reach a 15-letter improvement from baseline BCVA. ${ }^{54}$

Eyes receiving dexamethasone implants achieved a 15-letter improvement in BCVA significantly faster than did eyes receiving sham treatment (Figure 5).${ }^{54}$ The proportion of eyes achieving at least a 15-letter improvement from baseline BCVA was significantly greater in both dexamethasone implant groups than in the sham group from day 30 through day 90, with the greatest response (29\%) at day 60 $(P<0.001){ }^{54}$ The mean increase from baseline visual acuity was also significantly greater in both dexamethasone implant groups than in the sham group from day 30 through day 180 ( $P \leq 0.006$, Figure 6 ), with the greatest between-group difference (approximately 10 letters) at day $60 .{ }^{54}$ The mean decrease in central retinal thickness was significantly greater in both dexamethasone implant groups compared with the sham group at day $90(P<0.001)$ but not at day $180 .{ }^{54}$ 


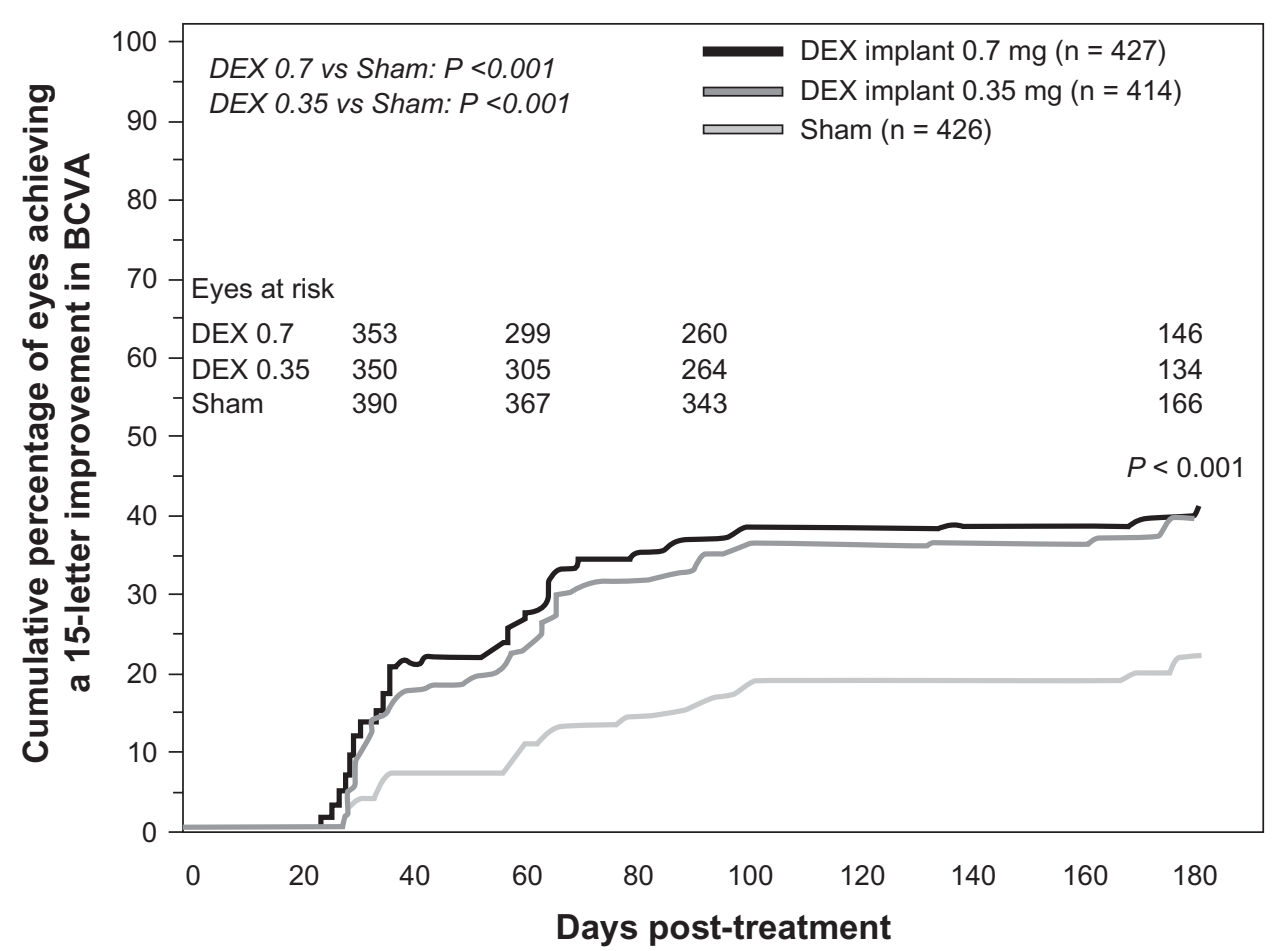

Figure 5 Time to achieve 15 letters of improvement from baseline BVCA in patients with macular edema secondary to central retinal vein occlusion or branch retinal vein occlusion who participated in the Phase III trials.

Abbreviations: DEX, dexamethasone; BVCA, best corrected visual acuity.

In a prospectively defined subgroup analysis, the key efficacy outcomes (time to 15-letter improvement, proportion of eyes achieving at least a 15-letter improvement, and mean change from baseline BCVA) were evaluated for the branch and central retinal vein occlusion populations separately. In general, the response to the dexamethasone implant in both subgroups was qualitatively similar to the response seen in

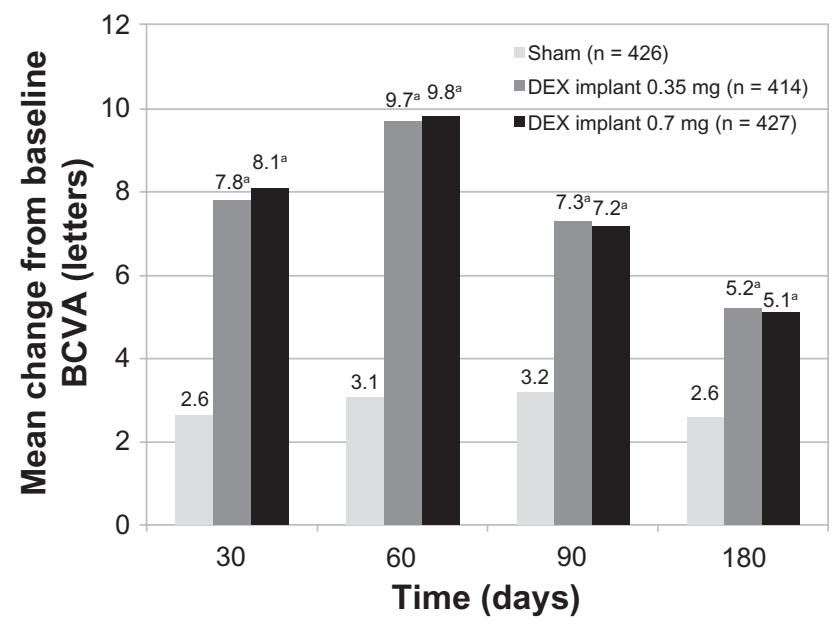

Figure 6 Mean change from baseline BVCA in patients with macular edema secondary to central retinal vein occlusion or branch retinal vein occlusion who participated in the Phase III trials.

Notes: ${ }^{a} \leq \leq 0.006$ compared to sham.

Abbreviations: DEX, dexamethasone; BVCA, best corrected visual acuity. the overall population, but the response in the sham group was greater in the branch retinal vein occlusion subgroup than in the central retinal vein occlusion subgroup in all efficacy analyses. The difference between the sham groups was particularly marked in the analysis of mean change from baseline BCVA (Figure 7). These findings support previous observations that central retinal vein occlusion is a more visually disabling disorder than branch retinal vein occlusion. Eyes with central retinal vein occlusion did not respond as well to therapy as eyes with branch retinal vein occlusion, and they were not improved without therapy. ${ }^{54}$

In the Phase III study, a post hoc subgroup analysis based on the duration of macular edema at baseline found that the response to the dexamethasone implant (proportion of eyes improving by $\geq 15$ letters and mean change from baseline BCVA) was often greater among eyes with a shorter duration of macular edema at baseline ( $\leq 90$ days) as compared with a longer duration ( $>90$ days) of macular edema. ${ }^{54} \mathrm{~A}$ similar effect of macular edema duration was seen in SCORE (Standard Care versus cOrticosteroid for REtinal vein occlusion study). ${ }^{34,54}$

In the Phase III study, the dexamethasone implant was well tolerated and associated with generally transient, moderate, and readily manageable adverse events. Those adverse events that occurred significantly more frequently in either dexamethasone implant group than in the sham 

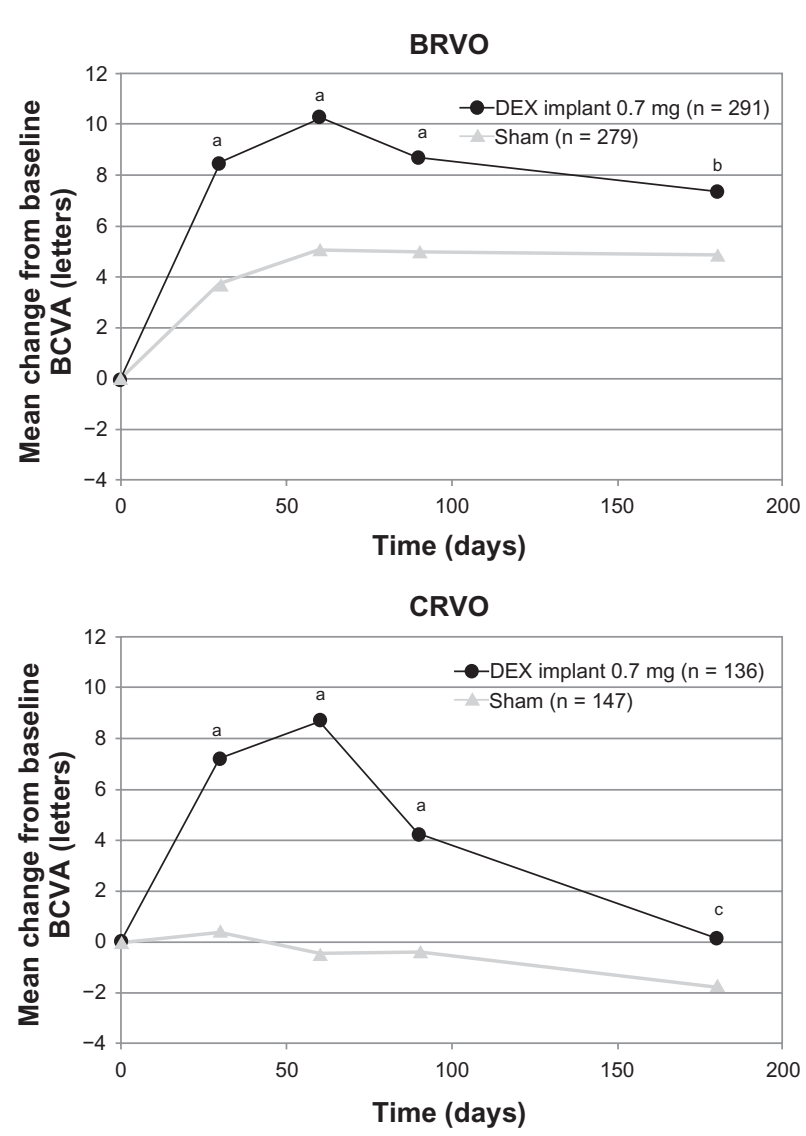

Figure 7 Mean change from baseline BCVA stratified by the underlying cause of macular edema of patients who participated in the Phase III trials.

Notes: ${ }^{a} P<0.001,{ }^{b} P=0.008$, and $c P=0.305$ compared to sham.

Abbreviations: DEX, dexamethasone; BVCA, best corrected visual acuity; BRVO, branch retinal vein occlusion; CRVO, central retinal vein occlusion.

group were eye pain $(P=0.023)$, anterior chamber cells $(P \leq 0.031)$, and ocular hypertension $(P \leq 0.002) .{ }^{54}$ The percentage of eyes receiving intraocular pressure-lowering medication increased in the dexamethasone implant groups from approximately $6 \%$ at baseline to $24 \%$ at day 180 , while there was no change in the sham group. Overall, the proportion of patients experiencing an intraocular pressure elevation of $\geq 10 \mathrm{mmHg}$ from baseline peaked at day 60 , and was less than $1 \%$ in the sham group and approximately $15 \%$ in both dexamethasone implant groups. ${ }^{54}$ There was no statistically significant difference between the treatment groups in the incidence of cataract. ${ }^{54}$ As with the Phase II studies, 180 days may not be long enough for detection of treatment-related cataract formation.

\section{Recent studies for other indications}

Recent clinical studies have evaluated the safety and efficacy of the dexamethasone implant as monotherapy for uveitic and diabetic macular edema. The efficacy of the dexamethasone implant in vitrectomized eyes is of particular interest because preclinical studies show that after implantation, vitreous and retinal dexamethasone concentrations in vitrectomized eyes are similar to those in nonvitrectomized eyes. ${ }^{55}$ The dexamethasone implant was also investigated as a combination therapy with laser photocoagulation in diabetic macular edema patients and with ranibizumab (Lucentis $^{\circledR}$, Genentech Inc, San Francisco, CA) in patients with choroidal neovascularization secondary to exudative age-related macular degeneration. The findings of these studies indicate that the dexamethasone implant significantly improves intraocular inflammation and visual acuity in uveitic macular edema patients, increases visual acuity in a difficult-to-treat vitrectomized population with chronic diabetic macular edema, and reduces the need for repeated ranibizumab injections in patients with choroidal neovascularization secondary to exudative age-related macular degeneration. ${ }^{55}$

\section{Conclusion}

Phase II and III studies indicate that the $0.7 \mathrm{mg}$ dexamethasone implant is consistently more efficacious than the $0.35 \mathrm{mg}$ dexamethasone implant. The response to treatment with the $0.7 \mathrm{mg}$ dexamethasone implant lasts for up to 180 days. Further studies are warranted to determine the response to repeated treatments, as well as the optimum retreatment interval in patients who require a longer duration of treatment. Nevertheless, clinical studies demonstrate that the dexamethasone implant is a promising new treatment option for patients with persistent macular edema resulting from retinal vein occlusion, diabetic retinopathy, and uveitis or Irvine-Gass syndrome. ${ }^{48-50,54}$ Further studies are warranted to support the clinical value of the dexamethasone implant in these patient populations.

Given the differences in patient populations, efficacy endpoints, and reporting of adverse events, it is not possible to compare directly the findings of the dexamethasone implant trials with those of the intravitreal triamcinolone acetonide trials. Head-to-head clinical studies are warranted to compare the safety and efficacy of the dexamethasone implant with those of intravitreal triamcinolone acetonide in macular edema patients. Mathematical models predict that placement of the dexamethasone implant in a more posterior vitreous location than the current anterior vitreous location maximizes macular drug exposure while minimizing anterior chamber drug exposure. Such a change in anatomical localization of the dexamethasone implant may further decrease the incidence of intraocular pressure elevation. ${ }^{56}$ 


\section{Disclosure}

Editorial assistance in the preparation of this manuscript was provided by Hadi Moini, $\mathrm{PhD}$, of Pacific Communications, a wholly-owned subsidiary of Allergan, Inc.

\section{References}

1. Ferris FL III, Patz A. Macular edema. A complication of diabetic retinopathy. Surv Ophthalmol. 1984;28 Suppl:452-461.

2. Durrani OM, Tehrani NN, Marr JE, Moradi P, Stavrou P, Murray PI. Degree, duration, and causes of visual loss in uveitis. Br J Ophthalmol. 2004;88(9):1159-1162.

3. Orth DH, Patz A. Retinal branch vein occlusion. Surv Ophthalmol. 1978;22(6):357-376.

4. Antonetti DA, Barber AJ, Khin S, Lieth E, Tarbell JM, Gardner TW. Vascular permeability in experimental diabetes is associated with reduced endothelial occludin content: Vascular endothelial growth factor decreases occludin in retinal endothelial cells. Penn State Retina Research Group. Diabetes. 1998;47(12):1953-1959.

5. Campochiaro PA, Hafiz G, Shah SM, et al. Ranibizumab for macular edema due to retinal vein occlusions: Implication of VEGF as a critical stimulator. Mol Ther. 2008;16(4):791-799.

6. Funatsu H, Yamashita H, Noma H, Mimura T, Yamashita T, Hori S. Increased levels of vascular endothelial growth factor and interleukin-6 in the aqueous humor of diabetics with macular edema. Am JOphthalmol. 2002;133(1):70-77.

7. Rossetti L, Autelitano A. Cystoid macular edema following cataract surgery. Curr Opin Ophthalmol. 2000;11(1):65-72.

8. Patel JI, Tombran-Tink J, Hykin PG, Gregor ZJ, Cree IA. Vitreous and aqueous concentrations of proangiogenic, antiangiogenic factors and other cytokines in diabetic retinopathy patients with macular edema: Implications for structural differences in macular profiles. Exp Eye Res. 2006;82(5):798-806.

9. Kiernan DF, Mieler WF. The use of intraocular corticosteroids. Expert Opin Pharmacother. 2009;10(15):2511-2525.

10. Mansoor S, Kuppermann BD, Kenney MC. Intraocular sustainedrelease delivery systems for triamcinolone acetonide. Pharm Res. 2009;26(4):770-784.

11. Ciulla TA, Rosenfeld PJ. Anti-vascular endothelial growth factor therapy for neovascular ocular diseases other than age-related macular degeneration. Curr Opin Ophthalmol. 2009;20(3):166-174.

12. Simo R, Hernandez C. Advances in the medical treatment of diabetic retinopathy. Diabetes Care. 2009;32(8):1556-1562.

13. Arnarsson A, Stefansson E. Laser treatment and the mechanism of edema reduction in branch retinal vein occlusion. Invest Ophthalmol Vis Sci. 2000;41(3):877-879.

14. Battaglia PM, Saviano S, Ravalico G. Grid laser treatment in macular branch retinal vein occlusion. Graefes Arch Clin Exp Ophthalmol. 1999;237(12):1024-1027.

15. Lardenoye CW, van Schooneveld MJ, Frits TW, Rothova A. Grid laser photocoagulation for macular oedema in uveitis or the Irvine-Gass syndrome. Br J Ophthalmol. 1998;82(9):1013-1016.

16. Morgan CM, Schatz H. Atrophic creep of the retinal pigment epithelium after focal macular photocoagulation. Ophthalmology. 1989;96(1): 96-103.

17. Roider J. Laser treatment of retinal diseases by subthreshold laser effects. Semin Ophthalmol. 1999;14(1):19-26.

18. Schatz H, Madeira D, McDonald HR, Johnson RN. Progressive enlargement of laser scars following grid laser photocoagulation for diffuse diabetic macular edema. Arch Ophthalmol. 1991;109(11): 1549-1551.

19. Leopold IH. Nonsteroidal and steroidal anti-inflammatory agents. In: Sears ML, Tarkkanen A, editors. Surgical Pharmacology of the Eye. New York: Raven Press; 1985.
20. Pagano G, Bruno A, Cavallo-Perin P, Cesco L, Imbimbo B. Glucose intolerance after short-term administration of corticosteroids in healthy subjects. Prednisone, deflazacort, and betamethasone. Arch Intern Med. 1989;149(5):1098-1101.

21. Robinson BH, Mattingly D, Cope CL. Adrenal function after prolonged corticosteroid therapy. Br Med J. 1962;1(5292):1579-1584.

22. Saag KG. Glucocorticoid-induced osteoporosis. Endocrinol Metab Clin North Am. 2003;32(1):135-157, vii.

23. Stanbury RM, Graham EM. Systemic corticosteroid therapy-side effects and their management. Br J Ophthalmol. 1998;82(6): 704-708.

24. Weijtens O, van der Sluijs FA, Schoemaker RC, et al. Peribulbar corticosteroid injection: Vitreal and serum concentrations after dexamethasone disodium phosphate injection. Am J Ophthalmol. 1997; 123(3):358-363.

25. Weijtens O, Schoemaker RC, Cohen AF, et al. Dexamethasone concentration in vitreous and serum after oral administration. Am J Ophthalmol. 1998;125(5):673-679.

26. Weijtens O, Feron EJ, Schoemaker RC, et al. High concentration of dexamethasone in aqueous and vitreous after subconjunctival injection. Am J Ophthalmol. 1999;128(2):192-197.

27. Weijtens O, Schoemaker RC, Romijn FP, Cohen AF, Lentjes EG, van Meurs JC. Intraocular penetration and systemic absorption after topical application of dexamethasone disodium phosphate. Ophthalmology. 2002;109(10):1887-1891.

28. Kwak HW, D'Amico DJ. Evaluation of the retinal toxicity and pharmacokinetics of dexamethasone after intravitreal injection. Arch Ophthalmol. 1992;110(2):259-266.

29. Beer PM, Bakri SJ, Singh RJ, Liu W, Peters GB III, Miller M. Intraocular concentration and pharmacokinetics of triamcinolone acetonide after a single intravitreal injection. Ophthalmology. 2003;110(4): 681-686.

30. Kamppeter BA, Cej A, Jonas JB. Intraocular concentration of triamcinolone acetonide after intravitreal injection in the rabbit eye. Ophthalmology. 2008;115(8):1372-1375.

31. Antcliff RJ, Spalton DJ, Stanford MR, Graham EM, Ffytche TJ, Marshall J. Intravitreal triamcinolone for uveitic cystoid macular edema: An optical coherence tomography study. Ophthalmology. 2001;108(4):765-772.

32. Ip MS, Kumar KS. Intravitreous triamcinolone acetonide as treatment for macular edema from central retinal vein occlusion. Arch Ophthalmol. 2002;120(9):1217-1219.

33. Martidis A, Duker JS, Greenberg PB, et al. Intravitreal triamcinolone for refractory diabetic macular edema. Ophthalmology. 2002;109(5): 920-927.

34. Ip MS, Scott IU, van Veldhuisen PC, et al. A randomized trial comparing the efficacy and safety of intravitreal triamcinolone with observation to treat vision loss associated with macular edema secondary to central retinal vein occlusion: The Standard Care vs Corticosteroid for Retinal Vein Occlusion (SCORE) study report 5. Arch Ophthalmol. 2009;127(9):1101-1104.

35. Scott IU, Ip MS, van Veldhuisen PC, et al. A randomized trial comparing the efficacy and safety of intravitreal triamcinolone with standard care to treat vision loss associated with macular edema secondary to branch retinal vein occlusion: The Standard Care vs Corticosteroid for Retinal Vein Occlusion (SCORE) study report 6. Arch Ophthalmol. 2009;127(9):1115-1128.

36. Diabetic Retinopathy Clinical Research Network. A randomized trial comparing intravitreal triamcinolone acetonide and focal/grid photocoagulation for diabetic macular edema. Ophthalmology. 2008; 115(9):1447-1449.

37. Armaly MF. Statistical attributes of the steroid hypertensive response in the clinically normal eye. I. The demonstration of three levels of response. Invest Ophthalmol. 1965;4:187-197.

38. Becker B. Intraocular pressure response to topical corticosteroids. Invest Ophthalmol. 1965;4:198-205. 
39. Butcher JM, Austin M, McGalliard J, Bourke RD. Bilateral cataracts and glaucoma induced by long term use of steroid eye drops. BMJ. 1994;309(6946):43.

40. Goldfien A. Adrenocorticosteroids and adrenocortical antagonists. In: Katzung BG, editor. Basic and Clinical Pharmacology. 6th ed. London: Prentice Hall International; 1995:592-607.

41. Ozurdex ${ }^{\circledR}$ [Package insert]. Irvine, CA: Allergan Inc; 2009.

42. Kobayashi H, Shiraki K, Ikada Y. Toxicity test of biodegradable polymers by implantation in rabbit cornea. J Biomed Mater Res. 1992; 26(11):1463-1476.

43. Visscher GE, Robison RL, Maulding HV, Fong JW, Pearson JE, Argentieri GJ. Biodegradation of and tissue reaction to 50:50 poly (DL-lactide-co-glycolide) microcapsules. J Biomed Mater Res. 1985; 19(3):349-365.

44. Barcia E, Herrero-Vanrell R, Diez A, Varez-Santiago C, Lopez I, Calonge M. Downregulation of endotoxin-induced uveitis by intravitreal injection of polylactic-glycolic acid (PLGA) microspheres loaded with dexamethasone. Exp Eye Res. 2009;89(2):238-245.

45. Cardillo JA, Souza-Filho AA, Oliveira AG. Intravitreal Bioerudivel sustained-release triamcinolone microspheres system (RETAAC). Preliminary report of its potential usefulness for the treatment of diabetic macular edema. Arch Soc Esp Oftalmol. 2006;81(12):675-681.

46. Herrero-Vanrell R, Refojo MF. Biodegradable microspheres for vitreoretinal drug delivery. Adv Drug Deliv Rev. 2001;52(1):5-16.

47. Kompella UB, Bandi N, Ayalasomayajula SP. Subconjunctival nano- and microparticles sustain retinal delivery of budesonide, a corticosteroid capable of inhibiting VEGF expression. Invest Ophthalmol Vis Sci. 2003;44(3):1192-1201.

48. Haller JA, Kuppermann BD, Blumenkranz MS, et al. Randomized controlled trial of an intravitreous dexamethasone drug delivery system in patients with diabetic macular edema. Arch Ophthalmol. 2010; 128(3):289-296.
49. Kuppermann BD, Blumenkranz MS, Haller JA, et al. Randomized controlled study of an intravitreous dexamethasone drug delivery system in patients with persistent macular edema. Arch Ophthalmol. 2007;125(3):309-317.

50. Williams GA, Haller JA, Kuppermann BD, et al. Dexamethasone posterior-segment drug delivery system in the treatment of macular edema resulting from uveitis or Irvine-Gass syndrome. Am J Ophthalmol. 2009;147(6):1048-1054.

51. Haller JA, Dugel P, Weinberg DV, Chou C, Whitcup SM. Evaluation of the safety and performance of an applicator for a novel intravitreal dexamethasone drug delivery system for the treatment of macular edema. Retina. 2009;29(1):46-51.

52. Chang-Lin JE, Attar M, Acheampong AA, et al. Pharmacokinetics and pharmacodynamics of the sustained-release dexamethasone intravitreal implant. Invest Ophthalmol Vis Sci. 2010 August 11. [Epub ahead of print].

53. Kuppermann BD, Chou C, Weinberg DV, Whitcup SM, Haller JA, Blumenkranz MS. Intravitreous dexamethasone effects on different patterns of diabetic macular edema. Arch Ophthalmol. 2010;128(5): 642-643.

54. Haller JA, Bandello F, Belfort R Jr, et al. Randomized, sham-controlled trial of dexamethasone intravitreal implant in patients with macular edema due to retinal vein occlusion. Ophthalmology. 2010;117(6): 1134-1146.

55. Data on file. Irvine, CA: Allergan Inc; 2010.

56. Lee SS, D'Argenio DZ, Moats R, et al. Pharmacokinetic modeling to improve the design of intravitreal corticosteroid implants for treating macular edema. Invest Ophthalmol Vis Sci. 2007; Abstr 0288.
Clinical Ophthalmology

\section{Publish your work in this journal}

Clinical Ophthalmology is an international, peer-reviewed journal covering all subspecialties within ophthalmology. Key topics include: Optometry; Visual science; Pharmacology and drug therapy in eye diseases; Basic Sciences; Primary and Secondary eye care; Patient Safety and Quality of Care Improvements. This journal is indexed on PubMed

Submit your manuscript here: http://www.dovepress.com/clinical-ophthalmology-journal

\section{Dovepress}

Central and CAS, and is the official journal of The Society of Clinical Ophthalmology (SCO). The manuscript management system is completely online and includes a very quick and fair peer-review system, which is all easy to use. Visit http://www.dovepress.com/testimonials. php to read real quotes from published authors. 